\title{
A INTEGRAÇÃO DA AGRICULTURA FAMILIAR COM ECONOMIA POPULAR E SOLIDÁRIA: UMA ANÁLISE DO PROCESSO DE AQUISIÇÃO NO PROJETO CANTINA SOLIDÁRIA I
}

\author{
$\underline{\text { Angélica Correia Lopes }{ }^{1} \text {; Alessandra Oliveira Teles². }}$
}

1. Bolsista PROBIC/UEFS, Graduanda em Agronomia, Universidade Estadual de Feira de Santana, e-mail: angelica.correia13@hotmail.com

2. Orientadora, Departamento de Ciências Humanas e Filosofia, Universidade Estadual de Feira de Santana, e-mail: alessandra.geografia@hotmail.com Solidária.

PALAVRAS-CHAVE: Comercialização; Agricultura Familiar; Economia Popular e

\section{INTRODUÇÃO}

A pesquisa insere-se no âmbito da Economia Popular e Solidária, ora apresentada como proposta de experiências que permitem a construção de um espaço pensando para além de uma visão econômica na busca de geração de trabalho e renda, tendo como alicerce a inclusão social dos sujeitos, levando em conta a sustentabilidade, o uso dos recursos naturais e conscientização ambiental.

Dentre os diversos formatos de iniciativas da economia popular e solidária, que se apresentam tanto no âmbito do campo como da cidade, onde compreende trabalhadores organizados coletivamente, têm-se: associações, grupos produtivos, cooperativas de agricultura familiar, redes de produção, comercialização e consumo, clubes de troca, bancos comunitários, cooperativas de crédito, fábricas recuperadas pelos trabalhadores. E em se tratando de tais grupos, as incubadoras universitárias tem desenvolvido um papel importante, de fornecer suporte para o seu desenvolvimento, fortalecimento e produção do conhecimento.

No que diz respeito à comercialização-base econômica para a geração de renda para o grupo, segundo Padilha Júnior (2006) “[...] entende-se por comercialização o desempenho de todas as funções ou atividades envolvidas na transferência de bens ou serviços do produtor ao consumidor final." O processo de comercialização ocorre desde o tempo mais antigos, com a prática do escambo que eram baseados em trocas naturais onde às partes decidiam livremente a quantidade de produtos que poderiam envolver as suas negociações. Com o aumento da população e áreas urbanas o processo de comercialização foi se aprimorando ao longo dos anos para poder atender a demanda dos consumidores.

Ao se tratar de comercialização de produtos regionais e desenvolvimento local o fortalecimento através de redes na própria comunidade, e cantina/comunidade se faz importante, pois a comercialização de alimentos da comunidade evidencia o desenvolvimento local, na medida em que os agricultores, principais responsáveis pelo crescimento dessa prática, e então, são visivelmente envolvidos no processo de produção de alimentos. Onde as matérias primas para elaboração dos alimentos são oriundas do local em que vivem, colocando em prática a valorização e fortalecimento da identidade do seu lugar.

Desta forma, o presente trabalho faz uma abordagem da execução do plano de pesquisa em iniciação científica durante o ano de 2017/2018 trazendo uma abordagem do período de agosto de 2017 até julho de 2018, distribuído em: metodologia, resultados e discussões além das considerações finais, buscando ampliar a integração entre pesquisa e extensão, o trabalho teve como objetivo discutir a articulação entre a Agricultura Familiar e Economia Popular e Solidária no processo de aquisição no Projeto Cantina Solidária III, na perspectiva do desenvolvimento local. 


\section{METODOLOGIA}

O enfoque da pesquisa foi baseado na Metodologia da Pesquisa Participante (BRANDÃO, 1999), onde pesquisadores e pesquisados são sujeitos de um mesmo trabalho comum, ainda que com situações e tarefas diferentes, combinando traços de pesquisa e extensão.

A pesquisa utilizou-se de um levantamento bibliográfico, que forneceu um suporte teórico sobre a temática de Metodologia Participante - Brandão (2007 e 1999); Economia Popular e Solidária e Desenvolvimento Local-Goerck e Fraga (2010); França Filho (2002); Lima (2012 e 2016); Agricultura Familiar e Ruralidade-Alentejano (2000); Carneiro (1998); Scneider (2003 e 2004); Graziano da Silva (1997); e Comercialização-Guimeiro (2009); Martins et al. (2012); Padilha Júnior (2006). Além de uma complementação teórica fornecida através de discussões do Grupo de Estudos e Pesquisa em Economia Popular e Solidária e Desenvolvimento Local (GEOPOSDEL).

Nesse contexto, o trabalho foi baseado em um levantamento de dados utilizando análises documentais de materiais realizados no mapeamento da comunidade de Lagoa Grande 2017. Ao passo que também foi realizado observação das atividades do grupo através de visitas em lócus e acompanhamento de algumas atividades formativas, que possibilitaram levantar dados de acordo com a vivência diária do grupo. Por fim, foi realizada a análise e interpretação dos dados e construção do relatório técnico final.

\section{Caracterização do grupo/local em estudo}

O Projeto Cantina Solidária III, caracteriza-se pela socialização dos meios de produção, trabalho coletivo autogestionário e práticas solidárias. Constitui da primeira experiência da IEPS com grupo rural do qual se leva à frente a incubação de um grupo mulheres trabalhadoras da Lagoa Grande, comunidade do distrito de Maria Quitéria, que atuam no espaço político-educativo-dialético-pedagógico da Cantina do módulo I.

O grupo informal Sabores do Quilombo, em processo de incubação desde julho de 2016- desenvolve suas atividades de produção e comercialização de alimentos com base na culinária local - o alimento é produzido pelas trabalhadoras e grande parte da matéria prima é fornecida pelos próprios agricultores da comunidade fortalecendo a rede de produção e comercialização local.

\section{RESULTADOS E DISCUSSÕES}

Entre os 106 agricultores/agricultoras entrevistados verificou-se que são produzidos na comunidade 19 produtos, sendo que a entrevista não se deteve a mensurar a quantidade produzida, mas somente se existia produção. Dentre estes 19 produtos pode-se dividir em três grupos levando em conta o percentual de agricultores /agricultoras que produzem estes produtos.

Grupo1 - É composto por 5 produtos, sendo que produzidos por mais de $50 \%$ dos agricultores.

Grupo 2-É composto por 8 produtos, sendo que estes produtos são produzidos por menos de $49,9 \%$ e mais de $10 \%$ dos agricultores.

Grupo 3 - É composto pelos 6 outros produtos, todos produzidos até 9,99\% dos agricultores.

No grupo 1 pode-se verificar que dos 5 produtos as frutíferas, são produzidos por quase todos (as) agricultores (as) e na maioria das vezes não é absorvida pela unidade familiar e acabam sendo desperdiçados, de modo que a comercialização nas Cantinas Solidárias- as frutas têm um grande espaço e valor considerado, seja para consumo in-natura, sucos de frutas, ou geladinho- podendo vir a ser, uma opção para esta parte de produtos que não é absorvida, estabelecendo outro aproveitamento para estes produtos ao passo que resolveria o problema do desperdício, além de possibilidade de geração de renda extra. 
No grupo 2 dos 8 produtos apenas o aipim, o feijão de corda e amendoim apresentam espaços de aquisição pela cantina. Sendo o aipim um dos carros chefes da cantina, de característica regional, participando da composição do cardápio, que apresenta frequência de saída durante todo período.

No grupo 3 apenas 3 produtos possuem direcionamento para aquisição na cantina, no entanto, a carne bovina, encontra-se como um dos produtos que são mais consumidos nos preparos diários dos pratos, no entanto, devido aos tamanhos das propriedades apenas um agricultor apresenta produção em função do se maior tamanho da propriedade.

Fatores como dispersão do setor rural, sazonalidade e pericibilidade dos produtos, influenciam diretamente a aquisição de produtos da comunidade para o espaço da cantina, pois a cantina exige um fluxo contínuo de produtos, que fazem parte da composição do cardápio, o qual a comunidade não produz ou produz em quantidade insuficiente para atender a demanda da cantina, sendo necessário recorrer para outros espaços de comercialização, como, por exemplo, o centro de abastecimento.

Desde o ingresso do grupo no espaço da cantina, sempre houve a aquisição de produtos da comunidade, no entanto, a venda direta de produtos in- natura dentro do espaço da cantina vem ganhando um espaço, principalmente de produtos alimentícios não convencionais-PANC'S, como forma de valorização e reconhecimento dos produtos da agricultura familiar, possibilitando a valorização de potencialidades, ainda subexploradas, promovendo a popularização destes produtos no meio acadêmico e promoção do desenvolvimento local na comunidade.

\section{CONSIDERAÇÕES FINAIS}

A comunidade de Lagoa Grande apresenta uma diversidade de produtos e/ou insumos locais que não são efetivamente valorizados comercialmente, em detrimento de outros de forte apelo em marketing nos mercados convencionais, mas, ainda assim a comunidade continua cultivando para utilização doméstica, sendo estas diversidades de produtos e/ou insumos, em sua maioria, não absorvidas pela unidade familiar e acabam se perdendo.

Neste sentido, esta parcela da produção que não é absorvida está sendo destinado para a comercialização nas Cantinas Solidárias da UEFS trazendo, desta forma, outro aproveitamento para aquele produto e possível geração de renda extra para aquele agricultor/agricultora criando atividades em redes que valorizem o bem viver e interação entre os produtores que vivem na mesma comunidade, favorecendo o desenvolvimento local, embora esse processo por si só não garanta uma estabilidade econômica local, salvo politicas públicas direcionadas a tal situação, o que, infelizmente, não se vislumbra perspectivas dada o baixo envolvimento do poder publico local no melhoramento da vida das classes populares ou vinculadas à economia plural.

Dessa forma, a comercialização dos produtos da comunidade pode certamente possibilitar uma relação de troca entre a comunidade local e a comunidade acadêmica, além de outras possibilidades, provendo assim o incentivo ao desenvolvimento local, estímulo a uma cultura alimentar tradicional e valorização da comunidade por vias de relações de consumo de uma alimentação mais saudável e uma produção associada.

\section{REFERÊNCIAS}

ALENTEJANO, Paulo Roberto R. O que há de novo no rural brasileiro? Terra Livre, São Paulo, n.15, p.87-112, 2000.

BRANDÃO, Carlos Rodrigues. Pesquisa Participante. São Paulo: Brasiliense, 1999. 
BRANDÃO, Carlos Rodrigues. A pesquisa participante: um momento na educação popular. Educação Popular, Uberlândia, v.6, p51-62. jan. /dez. 2007.

CARNEIRO, Maria José. Ruralidade: novas identidades em construção. Estudos Sociedade e Agricultura. Rio de Janeiro, v.11, p. 53-75, outubro 1998.

FRANÇA FILHO, Genauto Carvalho de. Terceiro Setor, Economia Social, Economia Solidária e Economia Popular: traçando fronteiras conceituais. Bahia Análise \& Dados. Salvador, SEI, v.12 n.1, p. 9-19, junho 2002.

GOERCK, Caroline; FRAGA Cristina Kologeski. Economia Popular e Solidária no Brasil: um espaço de resistência às manifestações de desigualdade da questão social. Vivências. Vol.6, n: 9: p.103-111, maio/2010.

GRAZIANO DA SILVA, J. O novo rural brasileiro. Nova Economia, Belo Horizonte, v.7, n.1, maio de 1997.

GUIMEIRO,G.D.Comércio Solidário e a comercialização da socioeconomia solidária no estado de Minas Gerais. Caminhos da Geografia, Uberlândiav. 10,n.31, dez/2009.

MARTINS, W.R. M, et al. Estratégias de comercialização dos produtos da agricultura familiar: um estudo de caso na comunidade Vale do Sol II, Tangará da Serra-MT. XXXII Encontro Nacional de Engenharia de Produção, Bento Gonçalves,mai/2012. análise dos

LIMA, J. R. O. Economia popular e solidária e desenvolvimento local solidário:

Processos educativos e de economia política inerente à incubação de iniciativas econômicas populares solidárias. Comunicação apresentada no I Seminário do Fórum de Pesquisa da Linha 3 - Educação, Gestão e Desenvolvimento Local Sustentável do PPGEduC/UNEB - Salvador-BA, mai.2012.

LIMA, J. R. O; LIMA, C. E. S. Economia Popular e Solidária e desenvolvimento local: relação protagonizada pela organicidade das iniciativas Outra Economia, Rio Grande do Sul, v.10, p.4. 2016.

PADILHA JÚNIOR, J.B. Comercialização de Produtos Agrícolas. Curitiba,p.128,2006.

SCHNEIDER, S. Teoria social, Agricultura Familiar e pluriatividade. Rev.bras.Ci.Soc, vol.18,n.51,fev 2003.

SCHNEIDER. S. A abordagem territorial no desenvolvimento rural e suas articulações externas. Sociologias, Porto Alegre, ano 6 ,n.11,2004. 